\title{
The Impact of China's Educational Institution Reform on China's Educational Resource Allocation and Discipline Structure
}

\author{
Ziteng Liu* \\ International Exchange College, Ningbo Institute of engineering, Ningbo, 315211, China, 1450662679@qq.com
}

\begin{abstract}
In this paper, I mainly study the impact of China's educational system reform on China's educational resource allocation and discipline structure. This paper will compare the changes of China's educational resources and discipline structure before and after the reform to reflect the impact of the educational system reform. The conclusion is: affected by this system reform, it will aggravate the imbalance of resource allocation, and make the discipline structure more inclined to the western structure system to a certain extent. It is hoped that this study can help China's education system develop in the right way and direction.Due to the short introduction time of this policy, there are almost no relevant papers on this content. Therefore, the research of this paper can make up for the academic gap of this part to a certain extent.
\end{abstract}

Keywords: resource allocation, discipline structure, Education marketization

\section{INTRODUCTION}

This paper consists of three parts. The first part expounds on the research background of this paper, that is, the Chinese government promulgated relevant laws and regulations to reform Chinese educational institutions in 2021.

After introducing the background of this study in the first part, it will turn to the second part to introduce in detail the impact of China's educational institution reform on China's educational resource allocation and discipline structure under the influence of this policy; For a better explanation, this part will divide the second part into three small arguments:

Firstly, this paper discusses the impact of this policy on the marketization of education and mainly expounds on the impact of this policy from three aspects;

Secondly, it discusses the impact of the policy on the allocation of educational resources from two aspects: short-term impact and long-term impact;

Finally, it examines the policy's influence on discipline structure, highlighting the impact by contrasting the discipline structure before and after its adoption.
In the third part, by consulting the contents of previous papers and relevant literature, this paper puts forward how to reasonably formulate relevant policies in the process of educational reform in order to solve some problems existing in China's education, such as the uneven distribution of educational resources;

Finally, combined with all the data, this paper will focus on the future development direction and trend of Chinese school education affected by this policy.

\section{RESEARCH BACKGROUND}

As far as China itself is concerned, the distribution of educational resources is very uneven, such as eastern coastal cities, such as Shanghai and Ningbo. The educational resources in economically developed areas such as Guangzhou are often better than those in many inland towns or economically backward regions like Guizhou and Guangxi.,and there are urban-rural differences.[1]They are mainly reflected in the following aspects: 1. Teacher resources: students in eastern coastal cities often receive high-quality educational resources from high-quality teachers who graduated from famous schools; For students in economically underdeveloped areas, because of the backward economy and inconvenient transportation, rarely have access to high-quality teacher resources; 2 . 
Opportunities for further education: for students in eastern coastal cities, due to the developed economy of the town, the number of schools will be much more than that in economically backward areas. Therefore, students in eastern coastal cities often have more opportunities for further education to help them access more high-quality educational resources; 3. Quality of educational resources: for students in eastern coastal cities, due to their developed economy and a high degree of ideological openness, they have not only more opportunities to access higher quality educational resources, but also different kinds of educational resources, such as computer programming, art painting, music, and musical instruments, but also for students in inland areas, All they can touch is a drop in the bucket that students in coastal cities can handle.

China's education has developed rapidly to a certain extent in recent years, and China has not implemented relatively strict control measures on the education market. Therefore, many out-of-school education institutions (such as XRS, one-to-one leaders, New Oriental, etc.) have suddenly emerged in the education market in recent years. To some extent, it helps to improve the current situation of an unbalanced distribution of educational resources in China:

On the one hand, these institutions often bring together teachers who graduated from many famous schools. They have rich knowledge reserves and educational skills, can provide students with high-quality and rich types of educational resources, and help to improve the situation that students in inland and other economically underdeveloped areas do not receive high-quality educational resources; On the other hand, thanks to the rapid development of science and technology, students can get high-quality educational resources at anytime and anywhere without leaving home and being limited by time and space, which can also improve the unbalanced distribution of educational resources to a certain extent.

As the advantages of educational institutions are gradually displayed in front of people, people realize that by making full use of the network and computer to carry out online teaching, we can realize complementary advantages and resource sharing to improve the coverage of high-quality resources and effectively solve the learning problems of low network coverage and slow network speed of students in inland cities and economically underdeveloped areas to a certain extent.

However, its disadvantages also appear. Due to the lack of market control, educational institutions in the education market have increased explosively. Especially in 2020, affected by the epidemic, capitalists saw the dividends brought by online education and educational institutions and began to set up educational institutions on a large scale. In recent months, due to inflation and rising prices, tuition fees of out-of-school tutorial institutions have increased year by year, which has become an essential part of family expenditure. People with fertility feel tremendous pressure on their future life.This situation seriously affects the implementation of the national three-child policy. Recently, the state has gradually realized the seriousness of the problem. To solve this problem, the Chinese government has issued applicable policies and regulations since March. For example, the opinions of the general office of the CPC Central Committee and the available office of the State Council on further reducing the burden of homework and after-school training of students in the stage of compulsory education put forward the concept of "double burden reduction policy," emphasizing that schools should improve the way of homework management and strengthen the primary role of school education, We will deepen the governance of out of school training institutions, resolutely prevent acts that infringe on the interests of the masses, create an excellent educational ecology, effectively alleviate parents' anxiety, and promote the all-round development and healthy growth of students. Restrict or even prohibit domestic educational institutions from providing out-of-school paid education for primary and secondary school students. Affected by this, China's out-of-school education institutions are forced to reform, which has a specific impact on the allocation of educational resources and discipline structure. [2]

\section{THE IMPACT OF THIS POLICY ON CHINA'S EDUCATIONAL RESOURCE ALLOCATION AND DISCIPLINE STRUCTURE}

\subsection{Impact on education marketization}

As mentioned in the research background, although the emergence of educational institutions can improve the unbalanced distribution of educational resources to a certain extent, due to the lack of market control, out-of-school educational institutions gradually move towards marketization over time. Therefore, with the gradual implementation of the policy, the disadvantages of education marketization are gradually exposed:

Rapid price rise: as early as 2016, among the families paying for tutoring, more than half of the primary and secondary school students spent 2000 10000 yuan per year on extracurricular counseling, and $13.7 \%$ of the families spent more than 20000 yuan per year. [3]Therefore, many low-income families have been unable to provide expensive tuition fees for a long time and have to give up tutoring institutions outside school. Affected by this, a large number of students will not be able to obtain high-quality educational resources. To some extent, it will even aggravate the unbalanced distribution of educational resources. 
The quality of educational resources is uneven, and the difference is enormous: under the influence of marketization, most educational institutions aim at making profits. Some educational institutions have the phenomenon of false publicity and even providing insufficient educational resources, which will even aggravate the uneven quality of educational resources to some extent.

The number of teachers in the school decreases, and the quality of educational resources in the school becomes worse. Due to the influence of marketization to recruit students, out-of-school educational institutions often recruit teachers with high salaries. To some extent, this will monopolize high-quality teacher resources, reduce the number and quality of teachers in schools, and impact China's educational resource allocation and discipline structure.

\subsection{Impact on the allocation of educational resources}

Due to the marketization of education, before implementing this policy, China's allocation of educational resources showed an aggravation of limited distribution. However, after the implementation of this policy, the after-school education industry collapsed rapidly. For the educational institutions affected by this policy, they need to start a large number of layoffs. According to the latest exclusive news, since August, ape counseling, homework help, and tail have begun to close some local centers: three of the 14 local homework help centers have been completed, and four primary school departments have been closed; Since the end of August, the number of personnel in the regional center has gradually decreased, and the Nanchang center has been completed; Eight of the 13 regional centers of Tal XRS online school will be canceled. Taking tools as an example, there are about 2000 people in each local center of XRS online school. The cancellation of eight will affect tens of thousands of people. [4]

Affected by this, in the short term, teachers in educational institutions have to face the problem of unemployment, which affects the employment rate and unemployment rate of China's education industry; For students and parents in some economically underdeveloped areas or areas with insufficient educational resources, they have lost the opportunity to obtain high-quality educational resources. Secondly, due to the deep-seated development of education marketization, after the introduction of this policy, the impact of economically underdeveloped areas on educational institutions is often more significant than that of economically developed areas, which will aggravate the imbalance in the allocation of educational resources in China to a certain extent, and there are fewer and fewer educational resources in economically underdeveloped areas [3]
However, many teachers in counseling institutions will re-enter society from out-of-school educational institutions in the long run. Since the number of teachers in schools in economically developed cities such as the eastern coast is complete, this group of teachers will take the initiative to go to cities in financially underdeveloped areas to take part in employment and educate students to a certain extent to seek a livelihood. Thus, it is conducive to the reallocation of educational resources to a specific time, making the distribution of educational resources more balanced than before.

\subsection{Impact on discipline structure}

Affected by this policy, the discipline structure will also change significantly. Before the promulgation of the policy, students were under tremendous pressure and had a fast pace of learning. To deal with various examinations, the subject structure was mainly examination subjects, and the installation was relatively single; After the promulgation of the policy, The less exam will reduce students' learning pressure, and their learning rhythm will be slower. Students have more time to learn other content, such as programming, painting, dance, etc., and the discipline structure will become more complex.

For teachers in educational institutions, they have to face the problem of unemployment, which affects the employment rate and unemployment rate of China's education industry; For students and parents in some economically underdeveloped areas or areas with insufficient educational resources, they have lost the opportunity to obtain high-quality educational resources. Secondly, due to the deep-seated development of education marketization, after introducing this policy, the impact on academic institutions in economically underdeveloped areas is often more significant than that in economically developed areas, which will exacerbate the imbalance in the allocation of educational resources in China to a certain extent. The educational resources in financially developed areas are more and more abundant, and the educational resources in financially backward areas are less and less [5]

\section{HOW TO REASONABLY FORMULATE RELEVANT POLICIES IN THE PROCESS OF EDUCATION REFORM}

In my opinion, to rationalize the system and policies in educational reform, we must solve the problem of the allocation of educational resources and deal with the issue of discipline structure. It can be considered from two dimensions: on-campus and off-campus. 


\subsection{At the school level}

As a school, we should pay attention to the diversification of education, do not overemphasize exam-oriented education, appropriately reduce the pressure on students, appropriately reduce the proportion of significant courses and increase the balance of minor procedures to facilitate students' learning pressure and reduce people's competition for educational resources, which can be more conducive to the rational allocation of educational resources to a certain extent. For example, reduce the number of examinations, appropriately reduce the number of tests in primary and secondary schools every semester and academic year, and make a comprehensive evaluation of students' achievements by observing the completion of students' daily homework and the interaction rate between students and teachers in the classroom.

We can appropriately reduce the number of examination-oriented courses, encourage students to actively participate in art, sports, and programming courses that help improve students' comprehensive quality development, and promote students' overall development. This helps enrich the discipline structure, make the discipline structure more complex, and is more conducive to education development.

\subsection{From the perspective of the National Government}

The government should control the development trend and speed of education marketization to make education marketization consistent with China's economic development trend, promote the marketization of education to be consistent with the trend of China's economic development, and control the development direction and speed of education marketization to make it compatible with the overall war of China's growth Consistent with the strategic law, promoting the development of socialism has Chinese characteristics.

Appropriately increase the number of schools. Through the previous research, it is not difficult to find that one of the important reasons for the uneven distribution of educational resources in China is that the number of schools in inland areas is too few compared with those in eastern areas, and many children have no chance to go to school, let alone receive education. Therefore, the government should build more schools in the economically underdeveloped inland areas. At the same time, we should also introduce educational resources suitable for students, and provide students with supporting learning resources while providing them with places to receive education.

Encourage fresh typical students to work in economically backward areas. By giving appropriate economic subsidies and encouraging new normal students to teach in remote areas, we can bring more high-quality educational resources to local students and help improve the imbalance in the distribution of educational resources. At the same time, we can also encourage teachers in economically developed eastern areas to set up relevant online teaching courses or use the Internet Technology, through webcast, network playback, and other forms, use the network to transmit the educational resources in the economically developed eastern areas to the inland areas in real-time, to help improve the imbalance of resource distribution to a certain extent

\section{CONCLUSION}

\section{The future development direction and trend of Chinese education}

In conclusion, according to the above analysis, it can be concluded that: In the short term, due to the impact of educational system reform, out-of-school educational institutions will collapse rapidly. Students in inland and other economically underdeveloped areas will lose the opportunity to obtain high-quality educational resources. In contrast, for students in Eastern financially developed regions, this will not have much impact. Therefore, this policy will aggravate the uneven distribution of educational resources in China to a certain extent. At the same time, the discipline structure in the education system is still relatively single. Students still only study major courses and don't care much about their comprehensive quality development.

In the long run, as the Chinese government begins to strengthen the control of the education market, the future development of China's education system will move towards the socialist education road. The government is expected to promote the rational allocation of educational resources through special regular students or the transfer of high-quality teachers in the future. Through the Internet and other means, the Internet and other means will effectively solve China's portion of educational resources. At the same time, due to the influence of western culture and the education system, the future development direction and trend of Chinese education will be close to the education types of western countries, that is, appropriately increase the attention of minor subjects and pay attention to the development of students' comprehensive quality. At the same time, the discipline structure will be further optimized. The addition of various other courses will make the discipline structure of Chinese education more complex.

Through research, we speculate that: From the perspective of development direction, Chinese education will tend to be diversified and in-depth in the future:

On the one hand, it is diversified. In the future, with 
the continuous development of China's economy, China may increase the coverage of compulsory education and reduce the pressure on students to enter school. As a result, China's education will no longer overemphasize exam-oriented education in the future but pay more attention to students' comprehensive quality education like the western education system. Therefore, students no longer only stay in the examination subjects but begin to learn issues that help improve their complete quality, such as programming, painting, and music, making China's education system more diversified to a certain extent.

On the other hand, is in-depth: at present, China's education level is relatively shallow, only focusing on simple knowledge understanding and examination application. In the future, China's education will develop to a deeper level, that is, deepen its integration, encourage students to innovate in thought or practice through learning to stimulate students' creative thinking, and cultivate students into talents with ingenious thinking. These new courses are also crucial for China's future development.

Finally, because this policy has been issued recently, on the one hand, this paper aims to make up for the blank of articles in related fields to a certain extent by studying the impact of China's educational system reform on China's educational resource allocation and discipline structure. To a certain extent, it can help latecomers understand the current situation of Chinese education; On the other hand, it is also hoped that specific discussion can provide some theoretical basis and suggestions for China to determine the direction of future education development, hope to contribute to the better improvement and development of China's education system, and help China solve the problem of uneven distribution of educational resources.

\section{REFERENCES}

[1] MicroLanguage.(2018) On the uneven distribution of educational resources in China from thedata.https://www.sohu.com/a/272335417_10029 3454

[2] Xinhua news agency. (2021) The general office of the CPC Central Committee and the general office of the State Council issued the opinions on further reducing the burden of homework and after-school training for students in the stage of compulsory education, www.moe.gov.cn/jyb_xxgk/moe_1777/ moe_1778/202107/t20210724_546576.html.

[3] Industrial Information Network.(2021)It is estimated that the scale of China's extracurricular counseling market will exceed 500 billion yuan by 2020, and a new round of education Nuggets is coming https://www.chyxx.com/industry/201811/694476.html
[4] Chen Jing (2021). Many layoffs have been made in front-line educational institutions such as ape counseling, homework helps and tall since August. Many layoffs have been made in front-line educational institutions such as ape counseling, homework helps and tall since August popularization of scientific and technological news and scientific and technological knowledge. https://www.zghy.org.cn/item/4513651 32463734784?ivk_sa=1023197a.

[5] Economics and law. ( 2020 ) "[heavy] online education under the tuyere, where are the challenges? www.sohu.com/a/385141554_354046 